https://doi.org/10.48009/2_iis_2010_114-121

\title{
THE AMERICAN RECOVERY AND REINVESTMENT ACT OF 2009 - HUMAN RESOURCES, ACCOUNTING, AND INFORMATION SYSTEMS ISSUES
}

\author{
Gloria Clark, Winston-Salem State University, clarkg@wssu.edu \\ Janice Witt Smith, Winston-Salem State University, jwsmithphd@nc.rr.com \\ Sharon D. White, Winston-Salem State University, whitesd@wssu.edu
}

\begin{abstract}
This paper reviews a major facet of the American Recovery and Reinvestment Act of 2009 - healthcare implementation issues as they relate to human resource management, accounting, and information technology use. Specifically, we look at the technological implications for the COBRA Coverage Extension, HIPAA, and Medicaid Expansions of the Act. There is a twofold purpose to this paper - to examine government regulation, organizational and people issues related to information technology and the need for its integration in both perspective and utility with other functional areas of the organization; and to analyze a specific fact situation in which there is a greater call for informational technologists to increase their knowledge about the organization (e.g., human resource management issues, accounting systems, and management reporting needs) because of increased federal regulations and employment laws which affect reporting and compliance requirements. In addition, based on our examination of the current regulatory, employment law, compliance, and financial environments, we have made several recommendations that would facilitate the effective and efficient use of technology in business organizations impacted by the American Recovery and Reinvestment Act and other federal and state regulations.
\end{abstract}

Keywords: American Recovery and Reinvestment Act, Human Resource Information Systems, Accounting Information Systems, Management Information Systems, Privacy Issues, COBRA, and HIPAA

\section{INTRODUCTION}

This paper reviews a major facet of the American Recovery and Reinvestment Act of 2009 - healthcare implementation issues as they relate to human resource management, accounting, and information technology use. Specifically, we look at the technological implications for the COBRA Coverage Extension, HIPAA, and Medicaid Expansions of the
Act. There is a twofold purpose to this paper - to examine government regulation, organizational and people issues related to information technology and the need for its integration in both perspective and utility with other functional areas of the organization; and to analyze a specific fact situation in which there is a greater call for informational technologists to increase their knowledge about the organization (e.g., human resource management issues, accounting systems, and management reporting needs) because of increased federal regulations and employment laws which affect reporting and compliance requirements.

\section{IT-Specific Issues}

Organizations' use of computerized information systems is the new norm, and the types of uses are both consistent and varied. It is unusual for business organizations not to have e-mail, personal financial applications, web browsers, and some type of access to social networks. Because of the pervasiveness and importance of the use of information technology in organizations, it is critical that the systems created by designers and implementers of information systems meet the needs of the organization and is accepted by the target audience. Unfortunately, this acceptance is not always the case, and there are a myriad of reasons why the systems fail $[9,19]$. Additionally, there are a number of systems that are abandoned in the midst of their design or construction [22], and those that do not fulfill the user expectations when implemented. Pivotal work by Davis in his proposal and revision of the Technology Acceptance Model (TAM) helps IT professionals to understand why end users will accept or reject the information systems created solely by the IT department. The two most critical reasons include the end users perceived usefulness of the system and the ease of using that system [7].

Among the recommendations made in the IT community was to include users formally as part of the development team [16]. Three ways to accomplish this task included user-oriented methodologies such as participatory design, usercentric design, and joint application development (JAD) [23]. Research has consistently shown that the 
failure of an IT system is not due to technological issues, but those that are related to organizational and psychological issues - the people side of the equation, if you will [3, 8, and 17].

Morgan and Mueller [21] examined issues with security of information systems and found that despite documented cases of un-approved access to computer systems in organizations, there is still a bias toward allowing access through passwords alone. Risky human behaviors that may compromise the systems include passwords that are easy to guess; use of post-it notes and other methods to tape the password to the computer screen; the use of the same password to access a number of different portals, including web-facing systems; sharing of "secret" passwords with others inside and outside the organization; using familiar names, dates, labels, and nicknames as the password and adding a number at the end for the "nth" time that that password has been used.

A major part of the ARRA involves the use of information systems in the areas of human resources and accountability, specifically information systems to facilitate managed healthcare. Similar to the mandates of the HIPAA regulations a few years ago, there are compliance issues for healthcare organizations who receive federal funding as part of the ARRA. Human resources, accounting, and information systems personnel must be keenly aware of the implementation issues of this act and the corresponding mandates. Two information systems issues will be at the forefront when carrying out the mandates of the ARRA - technology acceptance/implementation issues and security/privacy/ethical issues of managed healthcare.

This paper reviews the primary focal areas of the American Recovery and Reinvestment Act of 2009 (ARRA 2009), its increased technological requirements, and the impact of technology on both the people and financial sides of the "equation." While not the specific focus of this paper, we are cautioned that not only do employers have to be aware of the impact of the ARRA, but they must also understand and plan for how this law intersects with other federal employment laws and healthcare reform and the Patient Protection and Affordable Care Act (PPACA) of 2010.

\section{AMERICAN RECOVERY AND REINVESTMENT ACT 2009}

In 2009, the United States was on the brink of a major financial crisis of astronomical proportions. Volume XI, No. 2, 2010
The national debt was over $\$ 10$ trillion, with nearly $\$ 4$ trillion worth of retirement savings wiped out, the monetary system on the verge of collapse, $8.1 \%$ unemployment rate, record bank foreclosures, rising fuel cost, and an uncertain stock market. In an attempt to reverse the economic downturn, the 407page long American Recovery and Reinvestment Act of 2009 (ARRA 2009) was passed by the One Hundred Eleventh Congress of the United States of America and signed into law by President Barack Obama on February 17, 2009 [7]. The purposes of this act are fivefold: (1) to preserve and create jobs and promote economic recovery; (2) to assist those most impacted by the recession; (3) to provide investments needed to increase economic efficiency by spurring technological advances in science and health; (4) to invest in transportation, environmental protection and other infrastructure that will provide long-term economic benefits, and (5) to stabilize state and local government budgets, in order to minimize and avoid reductions in essential services and counterproductive state and local tax increases. In short, this Act was a $\$ 787$ billion recovery package whose intent was to quickly re-start the United States economy by creating new jobs and saving existing jobs [20]. In addition, this Act also impacted the income tax structure by making a variety of changes to income tax laws and reducing individual and corporate income tax collections. The President and the heads of federal departments and agencies were given the responsibility for managing and expending the allocated funds for the aforementioned purposes.

An artifact of this act is its requirement for increased technology to access and transmit information about the funds, creating electronic monitoring and reporting requirements, mandating information collection and repositories, and strongly encouraging upgraded AIS, HRIS, and/or MIS computer systems. Among the long-term investment goals of this Act are the computerizing of health records to reduce medical/healthcare costs. The following perspectives frame our discussion from three disciplines in understanding the implementation issues of this act: human resources, accounting, and information systems.

Human Resources. From an HR perspective, there is the need for more technologically savvy employees in collecting, retrieving, interpreting, and reporting information in their human resource information system (HRIS) as well as possible increased HR staff training costs and additional reporting requirements. The use of HRISs becomes increasingly important to capture employee data and to track applicants, current employees, exiting employees, and
Issues in Information Systems 
employees who have exited but still maintain eligibility for several benefits extended or created under ARRA. Furthermore, there is an increased need for internal education and coordination among HR, benefits, payroll and accounting, to ensure that there is a coordinated approach to compliance under this and other intersecting federal laws. In addition, the organization has additional reporting requirements and a greater need to track employee information for expanded unemployment benefits, most of which are done electronically. Secure storage of information, employee privacy, and secure access to the information all become increasingly important to the organization.

Accounting. Individuals in accounting and financial services also have additional and enhanced requirements as it relates to ARRA 2009. Many organizations have to make technology enhancements to access and track stimulus funds nationally and within their own company. Additionally more of the needed information is housed on government websites; there is usually an on-line application process; there are strict requirements for tracking money internally, where more sophisticated accounting information systems (AIS) may be required; and in some cases, there is a requirement for the tracking of minority- and woman-owned businesses and certification process to qualify for access to these funds.

Information Systems/Technology. Information systems implementation and management is an effective link to both the HR side of the equation and the financial side. Challenges of adopting and implementing enterprise-wide systems could have national and global implications; additionally, privacy, security and ethical issues surrounding medical and financial needs will be of utmost importance. The opportunities created with an integrative and coordinated approach to the use of information technology in the use of healthcare and finance are numerous to include central repositories of critical information, access by qualified personnel in disparate locations, and increased accuracy of information to provide better decision-making.

The following is an examination of the key workplace initiatives, and a lens from information technology (management information systems), accounting, and/or human resource (HR) management perspectives, help to identify the complexity of the technology implications under this act. We examine COBRA from an HR and financial services perspective and then overlay the increased technology requirements to meet the provisions under

Volume XI, No. 2, 2010 the original act and through the expansion created by the Recovery Act of 2009. It is critical that Information Technology, Human Resource and Financial Services professionals are knowledgeable about the Act's workplace initiatives and their implications. We begin with a review of the critical components of the act as it pertains to healthcare, specifically the implementation of the COBRA coverage, HIPAA and Medicaid concerns. We conclude the paper with recommendations for key players.

\section{HEALTHCARE - A PRIMARY FOCAL AREA OF ARRA 2009}

COBRA Coverage Extension. In 2007, approximately 46 million people in the United State did not have health insurance [3]. The percentage of employees covered by employers' health plans decreased and was at 46.9 percent in 2006 [5]. A component of the Act includes $\$ 150$ billion for extension of Consolidated Omnibus Budget Reconciliation Act (COBRA) Coverage [1]. Under COBRA, employers with twenty or more employees offer continuation coverage to individuals meeting several qualifying conditions. These exiting employees could purchase health insurance through their employer at the group rate even after leaving their employment with that organization. Once the employee has elected the continuation coverage, this coverage must continue for either 18 or 36 months (depending on eligibility) unless the employee fails to make the payments, the employee is insured under another group health plan with another employer, or the employer discontinues offering group health insurance to its current employees. The Act extended eligibility criteria and length of eligibility and provided some relief to employers. The extension of medical insurance eligibility has had significant implications for employers, both from an administrative workload viewpoint and in ensuring that the way that the expenses are reflected in their accounting as well as tracking eligibility periods for employees laid off at various times. For smaller companies with 20 or more covered employees, whose records are not automated and for larger corporations who have downsized part of their HR staff or outsourced this functional areas, another level of complexity has been added to record keeping and tax implications.

The Internal Revenue Service (IRS) has issued information to assist companies in how they claim credit for the COBRA medical premiums they pay for their former employees. Employers must maintain supporting documentation for all credit
Issues in Information Systems 
claimed, which include: (a) Declaration of the former employee's involuntary termination; (b) documentation of receipt of the employer's 35 percent share of the COBRA premium, including dates and amounts [13]; (c) with a self-insured plan, proof of the premium amount and of the coverage provided to eligible individuals; (d) proof of each eligible individual's eligibility for COBRA coverage at any time between September 1 and December 31, 2009, and proof of their election of COBRA coverage; (e) Record of Social Security numbers of all covered employees, amount of subsidy reimbursed for each covered employee, and the number of individuals for which the subsidy reimbursement is being requested. The COBRA extension has resulted in an increase in the number of individuals who have applied for COBRA assistance. These data are critical to both the employee and the organizations' proper evaluation of the length of time a former employee is covered under the act. The HRIS must be sufficiently sophisticated, with secure access provided as needed, and management reports generated to ensure that an eligible individual is not deleted, and an individual who is not eligible is not included. Because this also impacts the individual's covered dependents, that information and their continuing eligibility must also be captured. The sheer size and scope of the information makes the data almost unmanageable without the appropriate overlay of a well-designed management information system.

HIPAA Coverage. The Health Insurance Portability and Accountability Act (HIPAA) (42 U.S.C.S. 300gg-300gg-2 (2008) provides a certificate of creditable coverage for individuals who had been covered under a group health plan during a specified period, which allows them to be insured without evidence of insurability. HIPAA allows eligible individuals to enroll for health coverage when they lose their health coverage, get married or add a new dependent. Insurers and employers are not allowed to discriminate in enrollment and in premiums they charge based on health status-related factors. HIPAA also guarantees the availability of health insurance coverage for small employers and renewability of health insurance coverage for both large and small employers. Finally, HIPAA preserves the states' rights and authority to regulate health insurance and to expand the coverage provided under federal law. Again, there are more regulations around data collection and security that arise to determine which individuals are eligible for HIPAA.

Because of the provision of a federal health information repository under the Reinvestment and Volume XI, No. 2, 2010
Recovery Act, there is expressed concern that employers will have and use information about preexisting medical conditions. In order to reduce this concern and to provide for greater security of data and enforcement of HIPAA, Title XIII of the Recovery Act (known as the Health Information Technology for Economic and Clinical Health Act) was created. This act makes several changes to the Privacy and Security Rules of HIPAA, designed to improve the enforcement of HIPAA. Civil Monetary penalties were broadened, the states' attorney generals are responsible for enforcing HIPAA; gives financial incentives to complainants who were harmed by HIPAA violations; require mandatory investigations and penalties for willful neglect; and provide for civil enforcement of criminal matters [18].

Medicaid Expansions. A second $\$ 87$ billion provision of the healthcare focus relates to providing state funds under Medicaid for workers who were not covered under a group health insurance plan. Before the subsidy, COBRA health care cost for the typical worker was $\$ 8,800$, with the employee paying $22 \%$ of their healthcare premium. Under the stimulus subsidy, eligible terminated workers pay 35 percent of the COBRA premium, rather than $102 \%$ as required initially for terminated workers under COBRA. This $35 \%$ payment costs about $\$ 3,000$ annually. The remaining $65 \%$ of the COBRA premium is paid by the employer, with reimbursement by the federal government through tax credits. The 2010 Department of Defense Appropriations Act, signed by President Obama on December 19, 2009, has provided four main changes to the COBRA premium subsidy rules established under the Act and provided four notice requirements. The employer must be able to track and document these subsidies for tax credits through their HRIS and AIS [14].

\section{IMPLICATIONS OF THE ARRA}

\section{Human Resource Information Systems}

From a general HR perspective, significant and negative implications have arisen from the downturn in the economy. There is increased regulation concerning HR practices, particularly in the realm of accounting for benefits and for dealing with COBRA (tracking exiting employees, eligibility periods) as well as with unemployment assistance eligibility and payments. Additionally, when employees are extremely concerned about whether or not they can afford their housing, what may happen in terms of their jobs, and how their families could be negatively
Issues in Information Systems 
impacted, it is extremely difficult for them to be meaningfully engaged in the company's primary business. As a result, the company is not leveraging its most important and competitive advantage, its human resources. There is an increase in the knowledge information needs for the organization, both internally and externally, and the choice of appropriate technological interventions is critical.

In a September 2009 survey by the International Association for Human Resource Information Management (IHRIM 2009) of 150 HR leaders representing healthcare, manufacturing, banking/finance and nonprofit industries, nearly $70 \%$ said that they were "cautiously optimistic" about the economy; and that, in 2010, they would do more with less. About $6 \%$ of the respondents were from Africa, Asia, the European Union, and Eastern Europe with the approximately $94 \%$ remaining from North America. Twenty-six percent of the respondents indicated that they plan to "optimize currently implemented systems to get more return from their investments," while another $24 \%$ plan to implement previously purchased models; and $19 \%$ plan to consolidate multiple systems under one vendor.

Despite the increased reporting requirements under the new federal laws, $51 \%$ of the respondents stated that their human resource information technology (HRIT) budgets for 2010 would remain the same, while $30 \%$ expected to increase their budgets; and $19 \%$ expected a decrease. About $40 \%$ of the respondents said they plan to move forward in 2010 with new HR system project implementation, while 28.7 percent said they do not intend to do so. Around $31.6 \%$ were either undecided or unsure. Their 2010 budgets were expected to increase for HR software investments in performance management (31.1\%), business intelligence $(22.4 \%)$, e-recruiting and applicant tracking (21.3\%), and core HR management systems and on-boarding programs (20\% each).

Finally, 52.9\% delayed optional HRIT projects, 22\% reduced headcount in HRIT departments, and almost $50 \%$ implemented hiring freezes. Most of these companies indicated that they would not increase their budget for training and staff development, although $11 \%$ plan to spend more on HRIT hiring, $18 \%$ to increase investment in HRIT staff training, and almost $20 \%$ plan to spend more on consultants and contractors. Finally, about $45 \%$ indicated that the current economic conditions did not force HRIT purchase decisions in their companies [16].

\section{Accounting Information Systems}

Volume XI, No. 2, 2010
Billions of federal economic stimulus money earmarked for the states under the American Recovery and Reinvestment Act of 2009 (ARRA) has already been spent on health, education, infrastructure and other programs designed to create jobs and jump start the economy [10]. However, one of the biggest challenges states are facing is maintaining currency with the accounting information reporting systems necessary to capture every tax dollar spent. Many traditional accounting information reporting systems are not technologically advanced to satisfy the reporting requirements of the ARRA. According to John Gillespie, CIO, State of Iowa, the reporting demands are unprecedented. The process has been further complicated by a variety of factors, including exceedingly tight deadline and complex and changing federal reporting guidelines. Gillespie's team developed a tracking and reporting system using Excel spreadsheets rather than commercial stimulus-tracking tools. The data is then imported into a database, where it is aggregated, extracted and converted to an XML formatted report and submitted online to the federal government [10]. Federal agencies receiving stimulus money are required to file weekly financial reports on how they are spending the money and their specific activities involving ARRA funds. Deputy Director Ramesh Advani of the newly formed Massachusetts Recovery and Reinvestment Office stated that Massachusetts is in the process of developing an automated data gathering and analysis system that includes Oracle Corporation's business intelligence tools, data marts and data warehousing. This accounting information reporting system will be used system-wide for grants management and reporting of all budget program activities including ARRA reporting requirements [10].

Furthermore, this Act has impacted the way that the IRS views a variety of accounting entries, as well as in the way that the Federal Reserve responds through its fiscal policies. With the amount of information involved, including the sheer scope of the types of things funded under the act, there needs to be appropriate accounting information systems (AIS) at the governmental and business organizational levels. While there continues to be a high level of disagreement among economists and other financial experts in terms of the appropriate response to the economic challenges the U.S. and other countries are facing, there is a real need to track the financial allocations and to ensure that conditions of the Act are met. Finally, with the additional human resource information and accounting requirements, there is a greater need for management information systems (through accounting and human resource information
Issues in Information Systems 
systems) to capture, track, and integrate necessary information to remain in compliance with the Act.

\section{RECOMMENDATIONS AND CONCLUSIONS}

The ARRA's goal of restoring and promoting economic recovery is vast in its approach and forward-thinking in its requirement of information technology use. The act has several mandates for the recovery in the area of healthcare management that requires an integrated approach of several functional areas in business, medical institutions, and governments including human resources, accounting, and information systems management. From our examination of a portion of the act involving the computerization, reporting and accountability of healthcare concerns, we offer the following observations and recommendations.

\section{Awareness of impact of laws on operations of organizations}

Federal and state laws frequently create an obligation around technology that may have been unforeseen and unbudgeted at the time of their passing. In this case, the impact of the American Recovery and Reinvestment Act of 2009, as it interacts and interfaces with other federal laws related to sensitive data, is huge. Individuals in IT must have a deeper understanding of the issues and challenges faced by the departments that they support. In this way, they can anticipate needs and uses of information technology hardware and software. In addition, they will be able to make contributions at a strategic rather than a merely tactical level.

\section{Systems Analyses}

Frequent technological analyses, from the user perspective, need to be conducted and integrated with a technological audit. There are a number of practical applications from a human resource management perspective in terms of maintenance, security, storage, and access of data. The stress on the internal capabilities of the human capital in organizations may also have been underestimated. Flowcharts should be created, at the end user level, to understand with what other departments or databases they need to interface, how they interact, what areas are affected by changes in data in other areas, how the end customer is affected, and the costs of needed and proposed changes.

Volume XI, No. 2, 2010

\section{Additional Human Capital Investment}

There may be a greater need for training on additional hardware, software and new applications, as well as a heightened knowledge and understanding of security and privacy laws. IT "folks" need to be able to meaningfully converse with non-IT "folks" to ascertain their needs, usage of technology, capability of existing technology, systemic changes underway, and those needed futuristically. These conversations should be dialogues and not monologues. IT orientations should be conducted for all existing and new employees, to ensure that there is clear understanding about what currently exists, proposed changes, and things that cannot happen for a variety of reasons. The IT helpdesk must interact with organizational employees in an intentional and truly helpful manner, since the failure to comply with state and federal regulations has severe consequences for the organization.

\section{Risk Management}

IT policies must encompass both normal and extraordinary use of equipment and applications. "Tracking" devices and applications must be implemented with an awareness of the impact of increased surveillance on the morale of the company's employees and customers. Loss of privacy and heavy monitoring of employee work through technology, continues to be a major concern for labor unions and other employee groups. There must be balance between what the company needs to feel secure and what the employees need to feel valued and trusted. Other risk management areas include access to data at the appropriate levels; damage and sabotage to equipment and applications; potential for illegal, immoral or unethical access to sensitive and private information; unauthorized access to and/or transporting of data away from the proscribed site; selling of confidential information to third parties; and sharing of confidential information with individuals who have neither the right nor need to know.

\section{Expansion of current capacity with appropriate interfaces}

Because of the necessity for tighter accounting controls to ensure that monies allocated have been spent as required and variances accounted for, the accounting information systems must become increasingly sophisticated and generate the appropriate management reports for auditing and management decision making.
Issues in Information Systems 


\section{Cyber security}

Finally, given the continued incidences of hackers into what had seemed to be impregnable firewalls (e.g., Department of Defense, major financial services organizations, hospitals and universities), considerable risks exists that the collected data may be compromised. The organizations must conduct detailed and intensive technological security audits, shore up potential areas of illegal entry, provide sufficient data massage and scrambling to reduce the likelihood of breeches, continue to educate users on appropriate creation and use of passwords, and provide sufficient access to individuals with a need to know. As the federal and state governments become more involved in legislation around data collection, security, and dissemination, there will be a continuing and increased need for information technology professionals to hone their skills, develop stricter controls, limit unnecessary access, while still providing for the data needs of organizations.

\section{REFERENCES}

29 U.S.C.S. 1161-1167 (2008).

Anonymous (2009). Research and Markets: American Recovery and Reinvestment Act of 2009 Understanding Obama's Healthcare Reforms, Drug Week, p. 1609.

Au, N., Ngai, E., \& Cheng, T. (2008). Extending the understanding of end user information systems satisfaction formation: An equitable needs fulfillment model approach, MIS Quarterly, 32(1), 43-66.

Barr, Sarah (August 27, 2008). Census Bureau says fewer lack coverage; decrease reflects shift to public insurance. Daily Labor Report 166, D-15.

Broome, Jr., and J. Tol (2009). "Small Biz's Bailout: 2009 Recovery Act Promotes SBA Lending," 107.8 (2009): p.9.

Daily Labor Report 77 (April 22, 2008). "Number of workers with employer-provided health benefits trended downward since 1995, A-9.

Davis, F. (1989). Perceived usefulness, perceived ease of use, and user acceptance of information technology. MIS Quarterly, 13(3), 319-340.

Doherty, N. (2003). The impact of inadequacies in the treatment of organizational issues on information Volume XI, No. 2, 2010 systems development projects. Information \& Management, 41(1), 49-62.

Ewusi-Mensah, K. (1997). Critical issues in abandoned information systems development projects. Communications of the ACM, 40(9), 74-80.

Fox, Justin (November 2, 2009). "Is the Stimulus Helping?" Time, p. 40.

Graham, Chris (October 1, 2009). "Stimulus Package: Is It Getting the Job Done?" Financial Executive, 25.8, p. 62.

Hewitt Associates, 2009). COBRA Enrollment Spiked in Most Industries Experiencing Mass Layoffs.

http://www.hewittassociates.com/Intl/NA/en-

S/AboutHewitt/Newsroom/PressReleaseDetail.aspx? cid $=7133$

LaHood, Ray (September 30, 2009). Stimulus funds are going where they are needed." USA Today, 8A.

King, J. (November 2, 2009). ARRA Stimulus Reporting: The Basics, Computerworld, p. 27.

King, J. November 2, 2009). Follow the Money, Computerworld, pp 25-26.

Lin, W., \& Shao, B. (2000). The relationship between user participation and system success: a simultaneous contingency approach. Information \& Management, 37(6) 283-295.

Lorenzi, N. (2003). Organizational issues = change. International Journal of Medical Informatics, 69(23), 197-203.

Marlair, Liam (November 7, 2009). "Home Builders, sellers, praise Tax Credit." McClatchy-Tribune Business News.

McClure, D. (2007). From the CIO Trenches: Why Some Projects Fail and Others Succeed. Stamford, CT: Gartner Group.

Miller, S. (2009). Claiming the new COBRA Premium credits on payroll tax forms. http://www.shrm.org/hrdisciplines/benefits/Articles/P ages/COBRAcredit.aspx2/5/2010 .

Morgan, J. \& Mueller, J. (2010). Human factors in the effectiveness of password security. 
Oz, E. \& Sosik, J.J. (2000).Why information systems projects are abandoned: a leadership and communication theory and exploratory study. Journal of Computer Information Systems, 41(1), 6678.

Pekola, S., Kaarilahti, N., \& Pohjola, P. (2006). Towards formalized end-user participation in information systems development process: Bridging the gap between participatory design and ISD methodologies. Proceedings of the Ninth Participatory Design Conference (pp. 21-30). Trento, Italy: Association of Computing Machinery (ACM).

HRM (2009a). COBRA: Checklist for special election period and premium subsidy under American Recovery and Reinvestment Act (ARRA). http://www.shrm.org/TemplatesTools/(Samples/HRF orms/Pages/0209cobra.aspx2/5/2010). http://www.shrm.org/LegalIssues/FederalResources/ Pages/IntensifiedHIPAAEnforcementa 2/ 5/2010.

SHRM (2009b). Health Insurance Portability and Accountability Act (HIPAA) of 1996. http://www.shrm.org/LegalIssues/FederalResources/ FederalStatutesRegulationsandGuidance2/5/2010 .

)
SHRM (2009). Survey: HR Tech Plans to do more with less in 2010.

http://www.shrm.org/hrdisciplines/technology/Article s/Pages/HRTechSpending.aspx.... 5/2/10.

Smith, A. (2010). COBRA Subsidy Extension, Notice Requirement Changes Reviews.

http://www.shrm.org/LegalIssues/FederalResources/ Pages/COBRASubsidyExtensionReview.... 2/5/2010

Swearingen, M.J. (2009). Recovery Act Will Intensify HIPAA Enforcement.

http://www.shrm.org/legalIssues/Federal

Resources/Pages/IntensifiedHIPAAEnforcement... $\underline{2 / 5 / 2010}$

http://www.recovery.gov/Pages/home.aspx?=content/ $\underline{\operatorname{act} 2052010}$

U.S. Department of Labor (2010). (http://www.dol.gov).

U.S. Government (2010). (http://www.recovery.gov/Pages/home.aspx?q=conte nt/act 